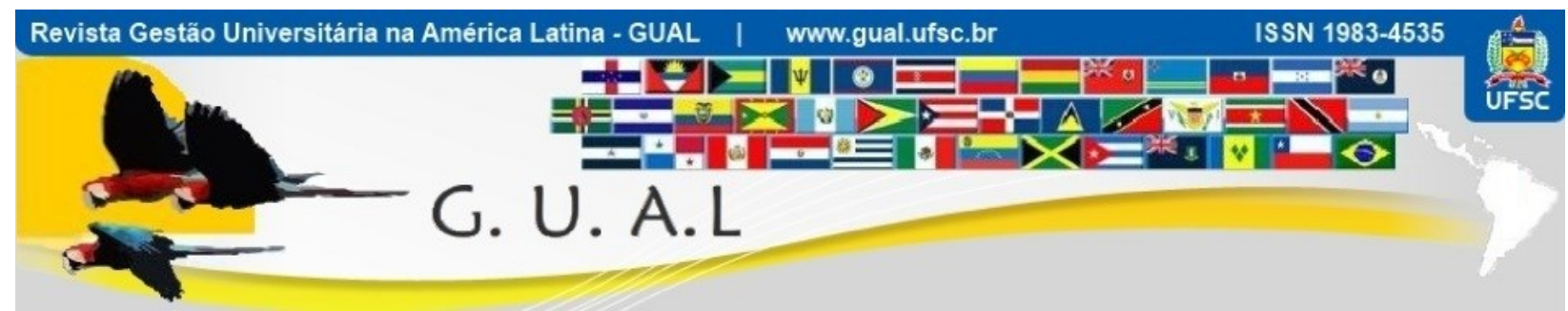

DOI: http://dx.doi.org/10.5007/1983-4535.2020v13n2p1

\title{
PERCEPÇÃO DOS ALUNOS DE CIÊNCIAS CONTÁBEIS SOBRE A ESTRUTURA CONCEITUAL BÁSICA DA CONTABILIDADE
}

\section{ACCOUNTING STUDENTS' PERCEPTION OF ON THE BASIC CONCEPTUAL FRAMEWORK OF ACCOUNTING}

\begin{abstract}
Daiani Schlup, Mestre
https://orcid.org/0000-0002-8052-6250 daianischlup@gmail.com

Fundação Universidade Regional de Blumenau | Programa de Pós-Graduação em Ciências Contábeis Blumenau | Santa Catarina | Brasil

Caroline Keidann Soschinski, Mestre https://orcid.org/0000-0002-0135-0729 carolinesoschinski@yahoo.com.br Fundação Universidade Regional de Blumenau | Programa de Pós-Graduação em Ciências Contábeis Blumenau | Santa Catarina | Brasil

Roberto Carlos Klann, Doutor https://orcid.org/0000-0002-3498-0938 rklann@furb.br

Fundação Universidade Regional de Blumenau | Programa de Pós-Graduação em Ciências Contábeis Blumenau | Santa Catarina | Brasil
\end{abstract}

Recebido em 05/dezembro/2018

Aprovado em 30/janeiro/2020

Publicado em 01/maio/2020

Sistema de Avaliação: Double Blind Review 


\title{
RESUMO
}

Objetivou-se analisar o entendimento dos alunos do curso de ciências contábeis sobre o conceito e a utilidade da estrutura conceitual no ensino de contabilidade. Para o levantamento de dados, foi utilizado um questionário estruturado, aplicado presencialmente no período de maio e junho de 2017, em acadêmicos do cursos de ciências contábeis de duas universidades de Santa Catarina, uma de caráter público e outra comunitária. Os dados dos 134 respondentes foram analisados considerando a diferença entre as universidades, gênero, experiência profissional e também o fato do respondente ter cursado, ou não, a disciplina de Teoria da Contabilidade. Os resultados apontam que a qualidade da informação contábil é o aspecto da estrutura conceitual que os acadêmicos têm menor domínio, sendo que os alunos da universidade pública tem mais dificuldade no assunto relativo ao valor justo, enquanto os da universidade comunitária apresentam maior dificuldade em relação ao objetivo da contabilidade. Como contribuições, aponta-se que diante das maiores dificuldades dos alunos, as universidades e professores podem modificar seus planos de ensino, procurando enfatizar tais temas. Também demonstra-se que os conceitos aprendidos no decorrer da disciplina são em parte "perdidos" na sequência, o que pode indicar a necessidade de alterações na didática utilizada pelos professores.

Palavras-chave: Estrutura Conceitual. CPC 00. Teoria Contábil. Ensino de Contabilidade no Brasil.

\begin{abstract}
The objective of this study was to analyze the students' understanding of the accounting sciences course on the concept and utility of the conceptual framework in accounting education. For the data collection, a structured questionnaire was used, applied in person in the period of May and June of 2017, in academics of the accounting sciences courses of two universities of Santa Catarina, one public and one community. The data of the 134 respondents were analyzed considering the difference between universities, gender, professional experience and also the fact that the respondent had or not attended the discipline of Accounting Theory. The results show that the quality of the accounting information is the aspect of the conceptual structure that the academics have less dominance, being that the students of the public university have more difficulty in the matter relative to the fair value, whereas those of the community university present greater difficulty in relation to the objective of accounting. As contributions, it is pointed out that faced with the greater difficulties of students, universities and teachers can modify their teaching plans, seeking to emphasize such themes. It is also demonstrated that the concepts learned during the course of the course are partly "lost" in the sequence, which may indicate the need for changes in didactics used by teachers.
\end{abstract}

Keywords: Conceptual Framework. CPC 00. Accounting Theory. Accounting Education in Brazil. 


\section{INTRODUÇÃO}

A Estrutura Conceitual para a Elaboração e Apresentação das Demonstrações Contábeis tem o objetivo de servir como fonte dos conceitos básicos e fundamentais a serem utilizados na elaboração e na interpretação dos Pronunciamentos Técnicos, assim como para a preparação e utilização das Demonstrações Contábeis das entidades, sendo elas comerciais, industriais ou outros negócios (CPC, 2008).

A Estrutura Conceitual Básica foi elaborada em 1973 pelo Financial Accounting Standards Board (FASB), que neste período, mudou o foco dos pronunciamentos contábeis tendo em vista a necessidade de estabelecer conceitos e orientações aos usuários da informação. Posteriormente, o International Accounting Standards Board (IASB) emitiu a sua Estrutura Conceitual Básica, que neste cenário, teve como objetivo fixar conceitos que fundamentassem a elaboração das demonstrações contábeis (PAULO, 2002). Em 2008, o Brasil aderiu à Estrutura Conceitual Básica por meio do Comitê de Pronunciamentos Contábeis (CPC) 00, que estabeleceu o detalhamento acerca dos conceitos e princípios contábeis, que servem como base estrutural para o ensino da contabilidade no país (PELEIAS et al., 2007).

De acordo com Godfrey et al. (2010), a estrutura conceitual deve fazer parte do ensino acadêmico por fornecer uma sólida base teórica, capaz de explicar conceitos da contabilidade e torná-los mais claros para os alunos.

A Teoria da Contabilidade é a base fundamental dentro de uma estrutura teórica da Ciência Contábil, considerando padrões e princípios. Pode ser definida como um conjunto de princípios hipotéticos, conceituais e pragmáticos que formam um mapa geral de conceitos para a investigação da natureza da contabilidade (HENDRIKSEN; VAN BREDA, 1999). Com o passar do tempo é possível observar cada vez mais a relevância dos conceitos fundamentais de contabilidade. Embora esta tenha passado por constantes transformações no decorrer dos anos, sua base teórica continua sendo a mesma (PEREIRA, 2008).

No Brasil, alguns estudos sobre o ensino da Teoria da Contabilidade já foram desenvolvidos, como o de Borba, Poeta e Vicente (2011), que verificaram junto aos programas de mestrado em contabilidade do Brasil, as ementas e bibliografias da disciplina Teoria da Contabilidade, de modo a relacionar o conteúdo proposto nas ementas e a bibliografia sugerida, com livros de relevância sobre o tema. Cruz, Ferreira e Szuster (2011) examinaram o nível de percepção dos docentes dos programas de pós-graduação stricto sensu 


\section{PERCEPÇÃO DOS ALUNOS DE CIÊNCIAS CONTÁBEIS SOBRE A ESTRUTURA CONCEITUAL \\ BÁSICA DA CONTABILIDADE \\ DOI: http://dx.doi.org/10.5007/1983-4535.2020v13n2p1}

em Ciências Contábeis acerca da Estrutura Conceitual para elaboração e apresentação das Demonstrações Contábeis no Brasil, enquanto Piccoli, Chiarello e Klann (2015) analisaram a percepção de acadêmicos sobre a disciplina de Teoria da Contabilidade.

Esses estudos anteriores tiveram enfoque na percepção de acadêmicos sobre a disciplina de Teoria da Contabilidade, nível de percepção de docentes de pós-graduação sobre estruturas conceituais ou ainda comparações sobre estruturas conceituais nacionais e internacionais. Porém, na literatura ainda não se observa estudos que utilizaram a aplicação de questionários para a comparação da percepção de acadêmicos sobre o conceito e utilidade da estrutura conceitual. Diante dessa lacuna, propõem-se o seguinte problema de pesquisa: Qual é o entendimento dos alunos de ciências contábeis sobre o conceito e a utilidade da estrutura conceitual no ensino de Contabilidade?

Dessa forma, o objetivo do estudo é analisar o entendimento dos alunos de Cursos de Ciências Contábeis de duas universidades localizadas no estado de Santa Catarina, sendo uma destas de caráter público e outra de caráter comunitária, sobre o conceito e a utilidade da estrutura conceitual no ensino de contabilidade.

A contribuição deste estudo consiste em ampliar a literatura sobre a estrutura conceitual no ensino de contabilidade, refletindo a importância da explicação desse conteúdo dentro da disciplina de Teoria da Contabilidade. Outra contribuição diz respeito às universidades, que poderão refletir sobre suas formas de ensino, diante da crescente procura por profissionais cada vez mais capacitados. Este estudo também pode contribuir com os órgãos reguladores, como o Conselho Federal de Contabilidade (CFC) e o Comitê de Pronunciamentos Contábeis (CPC), na medida que fornece subsídios sobre como os alunos e futuros profissionais percebem a importância da estrutura conceitual para sua formação, podendo indicar necessidades de ajustes na própria estrutura ou na forma como esta é apresentada aos alunos.

\section{REFERENCIAL TEÓRICO}

\subsection{EVOLUÇÃO DA ESTRUTURA CONCEITUAL E A TEORIA DA CONTABILIDADE}

O FASB foi responsável por iniciar a mudança do foco contábil em 1973, quando se voltou ao desenvolvimento de pronunciamentos sobre contabilidade financeira visando atender a demanda de informações dos usuários. Os pronunciamentos emitidos pelo FASB 


\section{PERCEPÇÃO DOS ALUNOS DE CIÊNCIAS CONTÁBEIS SOBRE A ESTRUTURA CONCEITUAL \\ BÁSICA DA CONTABILIDADE \\ DOI: http://dx.doi.org/10.5007/1983-4535.2020v13n2p1}

são denominados de Statements of Financial Accounting Concepts (SFACs) e possuem o objetivo de orientar os responsáveis sobre as normas e os padrões contábeis (PAULO, 2002).

De forma semelhante, o IASB emitiu a Estrutura Conceitual Básica que foi responsável por fixar os conceitos que fundamentam a elaboração das demonstrações contábeis afim de atender a demanda dos usuários externos. A intenção inicial do IASB em elaborar uma Estrutura Conceitual era também apoiar as futuras decisões da diretoria, tendo a estrutura como base teórica para o desenvolvimento de futuras normas contábeis (PAULO, 2002).

O Brasil apoiou a criação da Estrutura Conceitual para fundamentar o cenário contábil brasileiro e estabelecer princípios fundamentais da contabilidade. O Instituto dos Auditores Independentes do Brasil (IBRACON) incorporou aos seus pronunciamentos a Estrutura Conceitual, que posteriormente foi aprovada também pela CVM. Por fim, incorporou-se formalmente as práticas contábeis brasileiras como um pronunciamento contábil do Comitê de Pronunciamentos Contábeis (CPC), referendado pelo CFC (CVM, 1986; CPC, 2008).

O CPC 00 é reflexo do Framework emitido pelo IASB, assim como os demais CPCs, que são formulados e inseridos no ambiente contábil brasileiro de forma harmoniosa aos pronunciamentos internacionais. De acordo com o CPC 00 (2008), a Estrutura Conceitual para a Elaboração e Apresentação das Demonstrações Contábeis tem o objetivo de servir como fonte dos conceitos básicos e fundamentais a serem utilizados na elaboração e na interpretação dos Pronunciamentos Técnicos, assim como para a preparação e utilização das demonstrações contábeis das entidades, sendo elas comerciais, industriais ou outros negócios.

Para Iudícibus (2012), uma teoria pode ser caracterizada como um grupo de conceitos e definições que exibem uma visão de um evento, por meio da peculiaridade entre as variáveis com o objetivo de explicar esse determinado evento. Pode ser definida também como um conjunto coerente de postulados, princípios e restrições que definem uma ciência.

A base fundamental dentro da estrutura teórica da Ciência Contábil é a Teoria da Contabilidade, a qual se baseia em padrões e princípios. Essa teoria pode ser definida como um conjunto de princípios hipotéticos, conceituais e pragmáticos que formam uma estrutura geral de referências úteis para a investigação e para a explicação da natureza e dos fenômenos contábeis (HENDRIKSEN; VAN BREDA, 1999).

O objetivo que norteia a Teoria da Contabilidade é o de explicar e conseguir predizer um fenômeno ou prática da área contábil. Quando se consegue explicar junto à uma 


\section{PERCEPÇÃO DOS ALUNOS DE CIÊNCIAS CONTÁBEIS SOBRE A ESTRUTURA CONCEITUAL \\ BÁSICA DA CONTABILIDADE \\ DOI: http://dx.doi.org/10.5007/1983-4535.2020v13n2p1}

fundamentação na racionalidade natural os fenômenos contábeis, é possível fazer ciência, aguçando no pesquisador a necessidade de raciocinar, de analisar as variáveis e as suas relações de causa e efeito (WATTS; ZIMMERMAN, 1986).

A finalidade da estrutura conceitual básica é dar suporte na elaboração de novos pronunciamentos técnicos, assim como aos profissionais da área contábil ao prepararem as demonstrações contábeis, auxiliando também os auditores independentes na formulação de suas opiniões. O Pronunciamento Contábil CPC 00, que trata da estrutura conceitual, aborda os seguintes aspectos: os objetivos e usuários das demonstrações contábeis e suas necessidades de informação; os pressupostos básicos; as características qualitativas das demonstrações; os elementos das demonstrações; reconhecimento e mensuração destes elementos; e o conceito de capital e manutenção de capital (CRUZ et al., 2011).

O objetivo das demonstrações contábeis é fornecer informações sobre a posição patrimonial, o desempenho e as mudanças na posição financeira da entidade, que sejam úteis a um grande número de usuários em suas avaliações e tomadas de decisão econômica. Entre os usuários da contabilidade incluem-se investidores atuais e potenciais, empregados, credores por empréstimos, fornecedores, clientes, governos, entre outros (CPC, 2008).

As demonstrações contábeis retratam os efeitos patrimoniais e financeiros dos eventos da entidade, agrupando-os em classes de acordo com as suas características econômicas. Essas classes são chamadas de elementos das demonstrações contábeis. Os elementos diretamente relacionados à mensuração da posição patrimonial e financeira no balanço são os ativos, os passivos e o patrimônio líquido, e os relacionados com a mensuração do desempenho na demonstração do resultado são as receitas e as despesas. As características qualitativas são os atributos que tornam as demonstrações contábeis úteis para os usuários. As quatro principais características qualitativas são: compreensibilidade, relevância, confiabilidade e comparabilidade (CPC, 2008).

No que tange às diversas bases de mensuração contábil, pode-se empregar o custo histórico, em que os ativos são registrados pelos valores pagos ou a serem pagos em caixa ou equivalentes de caixa, ou pelo valor justo dos recursos que são entregues para adquiri-los na data da aquisição; custo corrente, em que os ativos são reconhecidos pelos valores em caixa ou equivalentes de caixa que teriam de ser pagos se esses ativos fossem adquiridos na data do balanço; valor realizável, em que os ativos são mantidos pelos valores em caixa ou equivalentes de caixa que poderiam ser obtidos pela venda numa forma ordenada; valor 
presente, em que os ativos são mantidos pelo valor presente, descontado, do fluxo futuro de entrada líquida de caixa que espera ser gerado pelo item no curso normal das operações da entidade (CPC, 2008).

Diante desses aspectos é possível observar a relevância do CPC 00 não apenas para o detalhamento dos conceitos e princípios contábeis, mas também como base para o ensino da contabilidade no Brasil, tópico abordado em seguida (CVM, 1986; CPC, 2008).

\subsection{ENSINO DA CONTABILIDADE NO BRASIL}

Inicialmente a contabilidade se desenvolveu predominantemente de forma prática, tendo ênfase apenas no método de partidas dobradas e na escrituração de livros contábeis. Durante muito tempo, a contabilidade foi considerada apenas um sinônimo de escrita, manutenção de livros de escrituração, apresentação de contas e responsável pela apresentação de saldos e andamento do negócio (SACRAMENTO, 1998).

De acordo com Iudícibus, Martins e Carvalho (2005), antes de ser considerada uma ciência, a contabilidade era vista como um sistema completo de escrituração, cujo maior sinônimo era o método de partidas dobradas. Porém, ao longo da história essa visão veio sendo reformulada, tendo a contabilidade recebido outros sentidos e significados.

Professores como Francisco D’Auria e Hermann Júnior destacam-se pelo fato de terem trazido ao Brasil indicativos de uma contabilidade com filosofia brasileira. Porém, tendo como base a filosofia italiana, esse ato influenciou a criação das primeiras normas contábeis no Brasil. Os primeiros passos do país rumo à teoria da contabilidade foram realizados pelos professores da Faculdade de Economia, Administração e Contabilidade da Universidade de São Paulo (FEA/USP), por meio de consultorias e trabalhos efetuados em empresas com regramento e auditoria americana, já que a implementação dessas empresas foi o que impulsionou o país a conhecer a filosofia anglo-saxônica e dar esses primeiros passos (SACRAMENTO, 1998).

A partir do século XXI houve uma mudança maior na concepção de contabilidade, que diz respeito à importância do ensino e suas condições de oferta, estando relacionados com o aumento da procura por profissionais que sejam qualificados e atuantes dentro de uma economia vinda do século XX (PELEIAS et al., 2007).

Iudícibus (1997) afirma que os grandes problemas que a contabilidade enfrenta não consistem da inadequação do conhecimento contábil em si, mas sim do erro de 
implementação de profissionais, que na verdade nunca foram treinados adequadamente na contabilidade moderna. Mesmo quando esses obtiveram um treinamento, o mesmo foi realizado de forma vaga, com aplicação parcial, sem um estudo rigoroso e reflexão crítica de suas causas, muito menos da sua evolução.

Segundo Sacramento (1998), essa afirmação feita por Iudícibus (2012) pode ser revertida, a partir do momento em que os futuros bacharéis obtenham, durante a fase da graduação, conhecimentos metodológicos e abrangentes na disciplina de Teoria da Contabilidade. $\mathrm{O}$ autor reforça que o professor tem que possuir conhecimento científico das ciências sociais, conseguir analisar o papel da teoria em relação aos fatos e vice e versa, conhecer as etapas para o desenvolvimento de uma teoria e ainda reforçar os princípios contábeis, a fim de realizar um treinamento adequado dos futuros profissionais da área.

Deve-se ainda reconhecer a Teoria da Contabilidade como um meio de otimizar e aumentar cada vez mais a capacidade da contabilidade ser útil aos seus usuários (PINHEIRO, 1997). Já que as práticas contábeis são produto do pensamento, ou melhor, da teoria, os objetivos e os conceitos da contabilidade devem sempre ser amparados e ter primazia sobre as práticas contábeis em qualquer regime de ensino (GLAUTIER; UNDERDOWN, 1995).

Desse modo, a Teoria da Contabilidade contribui para a formação do profissional contábil, que durante as disciplinas da graduação reflete sobre a contabilidade, abrindo um leque com diversos recursos e técnicas a serem utilizados, proporcionando ao aluno o entendimento dos objetivos, normas, princípios e conceitos fundamentais da contabilidade (MADEIRA; MENDONÇA; ABREU, 2003). Em suma, é evidente a importância do ensino da Teoria da Contabilidade, tanto para estudantes como para profissionais contábeis, já que a mesma serve como base para a solução de problemas práticos, assim como para a interpretação de situações que possam surgir no âmbito acadêmico e/ou profissional (BORBA et al., 2011).

\section{PROCEDIMENTOS METODOLÓGICOS}

Esta pesquisa se caracteriza como predominantemente quantitativa em consonância ao problema de estudo e exploratória no que se refere ao objetivo. A população da pesquisa compreendeu 202 acadêmicos matriculados na terceira, quinta e sétima fase do Curso de Ciências Contábeis de duas universidades localizadas no estado de Santa Catarina, sendo uma destas de caráter público e outra comunitária. A amostra foi intencional, classificada por 
acessibilidade, com 134 respondentes, caracterizando, assim, os alunos que já cursaram, estão cursando e vão cursar a disciplina de Teoria da Contabilidade.

O levantamento dos dados se deu por meio da aplicação de questionário estruturado durante os meses de maio e junho de 2017. Um pré-teste do questionário foi realizado com cinco professores que atuam na área da graduação e são mestres em contabilidade. Elaborouse o constructo da pesquisa, evidenciando as questões utilizadas no instrumento de coleta de dados, bem como de qual fonte essas questões foram adaptadas. O Quadro 1 sintetiza o constructo da pesquisa.

Quadro 1 Percepção dos alunos de ciências contábeis sobre estrutural conceitual

\begin{tabular}{|c|c|}
\hline Referências & Questões \\
\hline $\begin{array}{c}\text { Adaptado de } \\
\text { Piccoli, Chiarello } \\
\text { e Klann (2015) }\end{array}$ & $\begin{array}{l}\text { 1.1 A disciplina de teoria da contabilidade é importante para o seu aprendizado. } \\
1.2 \text { O aprendizado sobre estrutura conceitual das demonstrações contábeis é necessário } \\
\text { durante o curso. } \\
\text { 1.3 Os conceitos abordados sobre a estrutura conceitual na disciplina de Teoria da } \\
\text { Contabilidade são importantes para o entendimento das demais disciplinas do curso. }\end{array}$ \\
\hline $\begin{array}{c}\text { Conceitos } \\
\text { retirados de } \\
\text { Godfrey et al., } \\
\text { (2010); CPC 00 } \\
(2008) ; \text { Flegm } \\
(1984)\end{array}$ & $\begin{array}{l}\text { 2.1 Assinale o conceito que melhor se encaixa na definição de Estrutura Conceitual das } \\
\text { Demonstrações Contábeis: } \\
\square \text { Estrutura conceitual é um sistema de conceitos coerentes que fluem do objetivo do } \\
\text { relatório financeiro. Os conceitos abordam as operações, eventos e circunstâncias que } \\
\text { satisfazem as definições de elementos das demonstrações financeiras, a determinação de } \\
\text { quais itens devem ser reconhecidos nas demonstrações financeiras de uma entidade, como } \\
\text { esses itens devem ser mensurados, e como eles devem ser apresentados nas demonstrações } \\
\text { financeiras. } \\
\square \text { "Estrutura Conceitual para Elaboração e Divulgação de Relatório Contábil-Financeiro" } \\
\text { serve como fonte dos conceitos básicos e fundamentais a serem utilizados na elaboração e } \\
\text { na interpretação dos Pronunciamentos Técnicos assim como na preparação e utilização das } \\
\text { demonstrações contábeis. } \\
\square \text { A Estrutura Conceitual da Contabilidade deve ser entendida como uma "constituição" } \\
\text { para o processo de estabelecimento de normas ou padrões contábeis, além de fornecer um } \\
\text { conjunto de referências para solucionar questões contábeis na ausência de uma norma ou } \\
\text { padrão especifico, determinar limites de julgamento na preparação das Demonstrações } \\
\text { Contábeis, e aumentar comparabilidade, diminuindo o número de métodos contábeis } \\
\text { alternativos. }\end{array}$ \\
\hline $\begin{array}{l}\text { Adaptado do } \\
\text { Exame de } \\
\text { Suficiência do } \\
\text { CRC e Concursos } \\
\text { Públicos }\end{array}$ & $\begin{array}{l}\text { 3.1 No que se refere à posição patrimonial e financeira, assinale a opção INCORRETA: } \\
\square \text { Ativo é um recurso controlado pela entidade como resultado de eventos passados e do } \\
\text { qual se espera que fluam futuros benefícios econômicos para a entidade. } \\
\square \text { Passivo é uma obrigação presente da entidade, derivada de eventos passados, cuja } \\
\text { liquidação se espera que resulte na saída de recursos da própria entidade capazes de gerar } \\
\text { benefícios econômicos. } \\
\square \text { Patrimônio líquido é o interesse residual nos ativos da entidade depois de deduzidos } \\
\text { todos os seus passivos. } \\
\square \text { Receitas são aumentos nos benefícios econômicos durante o período contábil que } \\
\text { resultam em diminuições do patrimônio líquido e que estão relacionados com a contribuição } \\
\text { dos detentores dos instrumentos patrimoniais. } \\
3.2 \text { Sobre a Estrutura Conceitual para Elaboração e Divulgação de Relatório Contábil- } \\
\text { Financeiro, é INCORRETO afirmar que: } \\
\square \text { As características qualitativas fundamentais são comparabilidade, verificabilidade, } \\
\text { tempestividade e compreensibilidade, pois tornam a informação útil. A utilidade da }\end{array}$ \\
\hline
\end{tabular}




\begin{tabular}{|c|c|}
\hline Referências & Questões \\
\hline $\begin{array}{c}\text { Adaptado do } \\
\text { Exame de } \\
\text { Suficiência do } \\
\text { CRC e Concursos } \\
\text { Públicos }\end{array}$ & 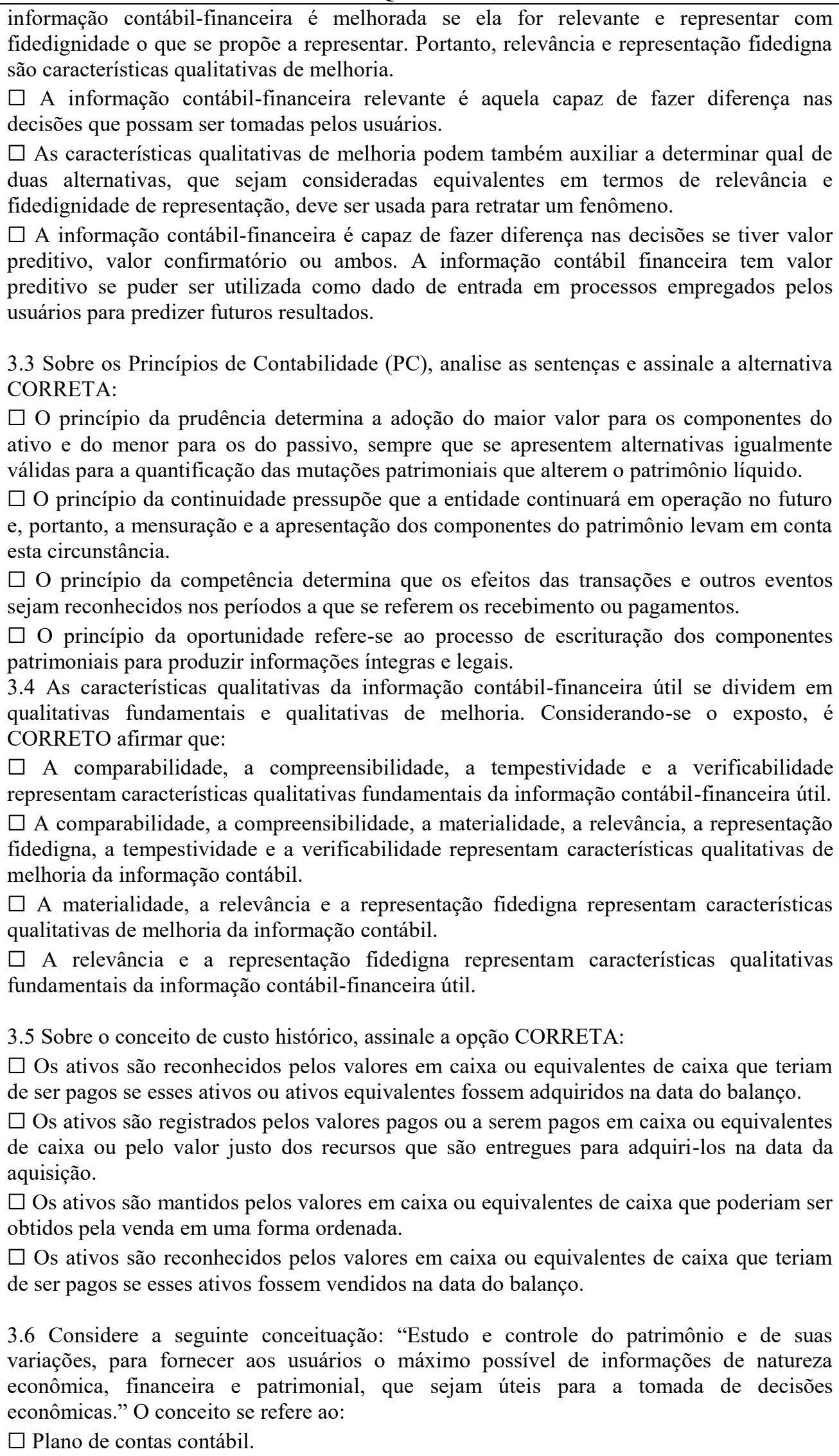 \\
\hline
\end{tabular}




\begin{tabular}{|c|l|}
\hline Referências & \multicolumn{1}{c|}{ Questões } \\
\hline & $\square$ Usuário da informação contábil. \\
& $\square$ Objetivo da contabilidade. \\
Adaptado do & $\square$ Campo de aplicação da contabilidade. \\
Exame de & 3.7 Na ausência de um mercado ativo para um determinado instrumento financeiro, o valor \\
Suficiência do & de um bem ou direito obtido por meio de modelos matemático-estatísticos de precificação \\
CRC e Concursos & de instrumentos financeiros é considerado: \\
Públicos & $\square$ Valor justo. \\
& $\square$ Valor atual. \\
& $\square$ Preço de mercado. \\
& $\square$ Valor financeiro. \\
\hline
\end{tabular}

Fonte: Elaborado pelos autores.

As questões do constructo estão separadas em três blocos. O primeiro buscou analisar a percepção dos alunos sobre a importância, a necessidade e a relação da estrutura conceitual com as demais disciplinas ministradas no curso de Ciências Contábeis, por meio da aplicação de três perguntas em escala Likert de cinco pontos, que vai de concordo totalmente (5) a discordo totalmente (1). O segundo bloco trata da análise da percepção dos acadêmicos sobre os conceitos da estrutura conceitual, verificada a partir da escolha entre três conceitos com diferentes níveis de complexidade.

No que se refere ao terceiro bloco, buscou-se analisar a interpretação teórica dos alunos quanto aos assuntos abordados na estrutura conceitual (CPC 00), por meio da aplicação de sete questões de múltipla escolha, pelo fato destas estarem relacionadas a uma Normativa Profissional, que deve ser estudada e aplicada pelos futuros contadores. A análise desses dados deu-se pela verificação da média de acertos das questões relacionadas ao aluno ter ou não cursado a disciplina de Teoria da Contabilidade.

Após a coleta dos dados estes foram tratados em planilhas do Microsoft Excel $^{\circledR}$ para a estatística descritiva. A primeira análise realizada procurou identificar o perfil do acadêmico respondente quanto ao gênero, idade, experiência profissional e se cursou a disciplina de Teoria da Contabilidade. Em seguida, foram realizados procedimentos estatísticos por meio do software SPSS ${ }^{\circledR}$, para verificar se havia diferença significativa entre as respostas de alunos de universidade pública ou comunitária, do gênero masculino ou feminino, com ou sem experiência profissional, verificando também a porcentagem de acertos das questões de alunos que já cursaram, estão cursando e não cursaram a disciplina de Teoria da Contabilidade. 


\section{APRESENTAÇÃO E ANÁLISE DOS RESULTADOS}

Neste tópico apresentar-se-á a análise dos resultados da pesquisa. Primeiramente, buscou-se delinear o perfil dos alunos respondentes, que são apresentados na Tabela 1 .

Tabela 1 Perfil dos Respondentes - Faixa Etária e Gênero

\begin{tabular}{c|c|c|c|c|c|c}
\hline & \multicolumn{2}{|c|}{ Universidade pública } & Universidade comunitária & \multicolumn{2}{c}{ Total } \\
\hline Faixa Etária & Frequência & $\mathbf{\%}$ & Frequência & $\mathbf{\%}$ & Frequência & $\%$ \\
\hline 16 a 19 anos & 14 & $27 \%$ & 16 & $19 \%$ & 30 & $22 \%$ \\
\hline 20 a 23 anos & 19 & $37 \%$ & 48 & $58 \%$ & 67 & $50 \%$ \\
\hline 24 a 27 anos & 12 & $24 \%$ & 11 & $13 \%$ & 23 & $17 \%$ \\
\hline 28 a 30 anos & 5 & $10 \%$ & 0 & $0 \%$ & 5 & $4 \%$ \\
\hline Acima de 30 anos & 1 & $2 \%$ & 8 & $10 \%$ & 9 & $7 \%$ \\
\hline Total & $\mathbf{5 1}$ & $\mathbf{1 0 0} \%$ & $\mathbf{8 3}$ & $\mathbf{1 0 0 \%}$ & $\mathbf{1 3 4}$ & $\mathbf{1 0 0 \%}$ \\
\hline Gênero & Frequência & $\mathbf{\%}$ & Frequência & $\mathbf{\%}$ & Frequência & $\%$ \\
\hline Masculino & 14 & $27 \%$ & 27 & $33 \%$ & 41 & $31 \%$ \\
\hline Feminino & 37 & $73 \%$ & 56 & $67 \%$ & 93 & $69 \%$ \\
\hline Total & $\mathbf{5 1}$ & $\mathbf{1 0 0 \%}$ & $\mathbf{8 3}$ & $\mathbf{1 0 0 \%}$ & $\mathbf{1 3 4}$ & $\mathbf{1 0 0 \%}$ \\
\hline
\end{tabular}

Fonte: Dados da pesquisa (2017).

Analisando a Tabela 1 na coluna total, percebe-se que metade da amostra tem idade entre 20 e 23 anos e apenas 14 respondentes (11\% da amostra) tem mais que 28 anos, caracterizando-se como uma amostra consideravelmente jovem. Quanto ao gênero dos respondentes, há predominância do gênero feminino, com mais de $2 / 3$ da amostra total.

Já ao comparar as universidades analisadas no presente estudo, verifica-se que ambas possuem um público bastante jovem, porém, destaca-se o fato de a instituição pública ter cerca de $58 \%$ dos seus estudantes em uma faixa etária entre 20 e 23 anos, enquanto a universidade comunitária tem um público mais distribuído entre 16 a 27 anos.

Quanto à comparação de gênero entre as universidades, observa-se que em ambas as instituições há predominância de gênero feminino, caracterizando $73 \%$ da amostra na universidade pública e $67 \%$ na universidade comunitária. A Tabela 2 apresenta dados referentes à experiência profissional dos participantes.

Tabela 2 Perfil dos Respondentes - Experiência Profissional na Área Contábil

\begin{tabular}{c|c|c|c|c|c|c}
\hline & \multicolumn{2}{|c|}{ Universidade pública } & Universidade comunitária & \multicolumn{2}{c}{ Total } \\
\hline $\begin{array}{c}\text { Experiência } \\
\text { Profissional }\end{array}$ & Frequência & $\mathbf{\%}$ & Frequência & $\mathbf{\%}$ & Frequência & $\%$ \\
\hline Possui & 18 & $35 \%$ & 41 & $49 \%$ & 59 & $44 \%$ \\
\hline Não possui & 33 & $65 \%$ & 42 & $51 \%$ & 75 & $56 \%$ \\
\hline Total & $\mathbf{5 1}$ & $\mathbf{1 0 0} \%$ & $\mathbf{8 3}$ & $\mathbf{1 0 0 \%}$ & $\mathbf{1 3 4}$ & $\mathbf{1 0 0 \%}$ \\
\hline
\end{tabular}

Fonte: Elaborado pelos autores (2017). 


\section{PERCEPÇÃO DOS ALUNOS DE CIÊNCIAS CONTÁBEIS SOBRE A ESTRUTURA CONCEITUAL \\ BÁSICA DA CONTABILIDADE \\ DOI: http://dx.doi.org/10.5007/1983-4535.2020v13n2p1}

Observa-se na Tabela 2, na coluna total, que a maioria dos alunos matriculados no curso de Ciências Contábeis das duas universidades pesquisadas neste estudo (56\% da amostra) ainda não tem experiência profissional na área contábil, sendo que dos 134 respondentes, apenas 59 afirmam ter experiência. Porém, verifica-se que os estudantes da universidade comunitária estão mais presentes no mercado de trabalho, pois $49 \%$ da amostra têm experiência profissional na área, enquanto na universidade pública esse índice é de apenas 35\%. A Tabela 3 apresenta dados relativos aos respondentes terem cursado ou não a disciplina de Teoria da Contabilidade.

Tablela 3 Perfil dos Respondentes - Já cursou, está cursando, ou não cursou a disciplina

\begin{tabular}{l|c|c|c|c|c|c}
\hline \multirow{2}{*}{$\begin{array}{c}\text { Disciplina da } \\
\text { Teoria da } \\
\text { Contabilidade }\end{array}$} & \multicolumn{2}{c|}{ Universidade pública } & Universidade comunitária & \multicolumn{2}{c}{ Total } \\
\cline { 2 - 7 } & Frequência & $\%$ & Frequência & $\%$ & Frequência & $\%$ \\
\hline Já cursou & 23 & $45 \%$ & 38 & $46 \%$ & 61 & $46 \%$ \\
\hline Está cursando & 9 & $18 \%$ & 20 & $24 \%$ & 29 & $22 \%$ \\
\hline Não cursou & 19 & $37 \%$ & 25 & $30 \%$ & 44 & $33 \%$ \\
\hline Total & $\mathbf{5 1}$ & $\mathbf{1 0 0} \%$ & $\mathbf{8 3}$ & $\mathbf{1 0 0 \%}$ & $\mathbf{1 3 4}$ & $\mathbf{1 0 0 \%}$ \\
\hline
\end{tabular}

Fonte: Elaborado pelos autores (2017).

Ainda sobre o perfil dos respondentes, ao se comparar a amostra de estudantes das duas universidades pesquisadas, percebe-se que apresentam distribuição semelhante, com a maioria dos alunos já tendo cursado ou que estão cursando a disciplina. Portanto, aproximadamente $1 / 3$ da amostra em ambas as universidades ainda não teve tal formação, o que é importante para analisar se a disciplina realmente está fazendo diferença na formação do aluno de Ciências Contábeis. A Tabela 4 demonstra os dados do primeiro bloco de questões, que apresenta qual a percepção dos acadêmicos sobre a Estrutura Conceitual das Demonstrações Contábeis.

Os dados da Tabela 4 apontam que 42 alunos da universidade pública acreditam que a disciplina de Teoria da Contabilidade é importante para seu aprendizado, dos quais 22 concordam com a afirmação e 20 concordam totalmente, representando $82 \%$ dos respondentes. Já no que se refere aos alunos da universidade comunitária, 33 concordam com a afirmação e 29 concordam totalmente, representando $75 \%$ da amostra, sendo que $23 \%$ dos respondentes são indiferentes quanto à importância da disciplina.

Ao realizar um teste de média entre as respostas dos alunos da universidade pública e privada, gênero masculino e feminino, com ou sem experiência e os que cursaram e não cursaram a disciplina, percebe-se que para a questão 1.1 houve diferença estatisticamente 
significativa apenas entre as respostas dos estudantes de gênero masculino e feminino, com significância de 0,013 .

Tabela 4 Percepção sobre a Estrutura Conceitual das Demonstrações Contábeis

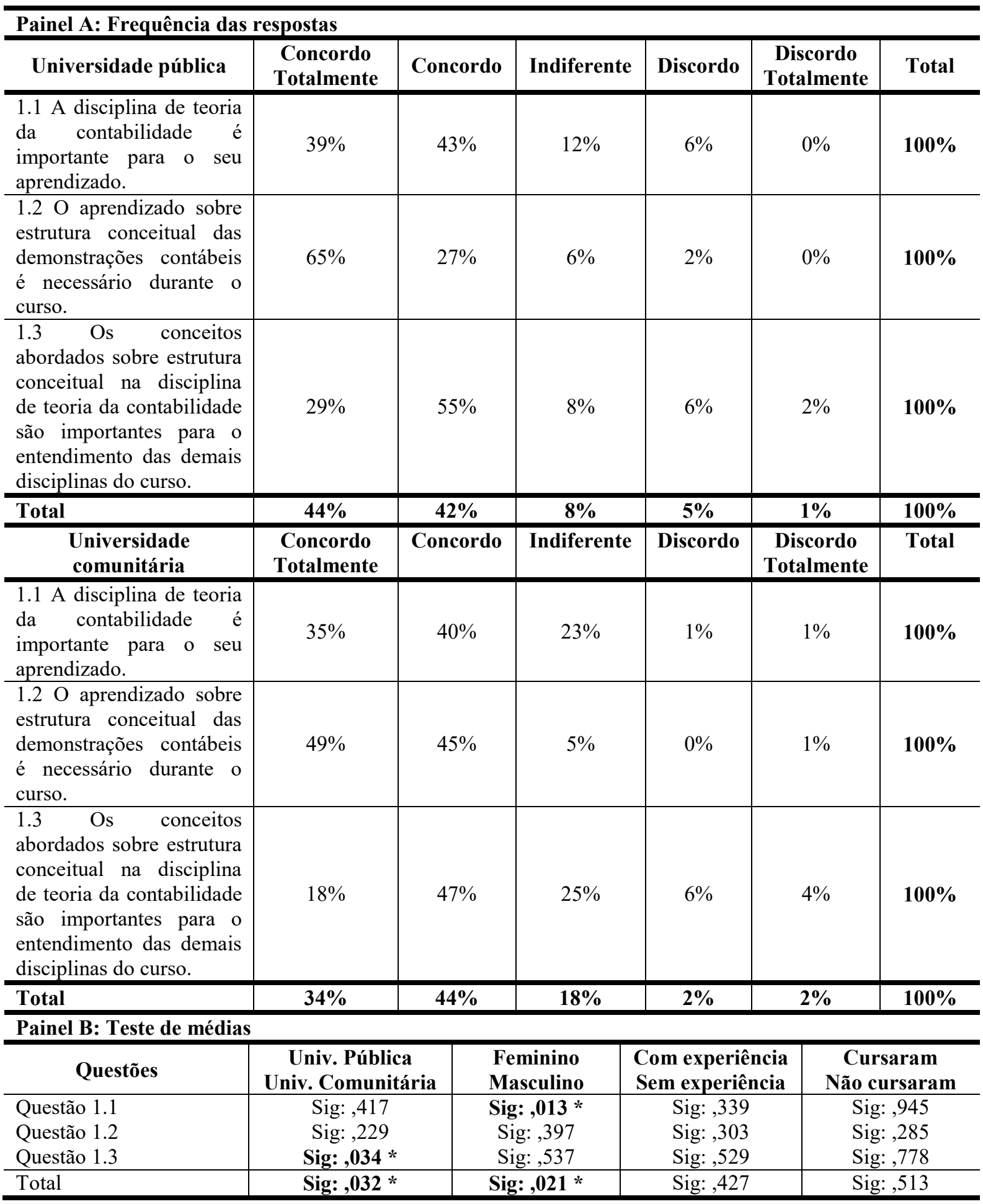

Fonte: Elaborado pelos autores. 


\section{PERCEPÇÃO DOS ALUNOS DE CIÊNCIAS CONTÁBEIS SOBRE A ESTRUTURA CONCEITUAL

No que tange ao aprendizado sobre a estrutura conceitual das demonstrações contábeis ser necessário para o curso, o estudo identificou na universidade pública um percentual de $92 \%$ dos respondentes, em que 14 concordam e 33 concordam totalmente. Na universidade comunitária também foi possível identificar um percentual elevado de convergência da questão, representando $94 \%$ da amostra, em que que 37 respondentes concordam e 41 concordam totalmente. Quanto à diferença nas médias das respostas, percebe-se que para questão 2.2 não houve diferença estatisticamente significativa para nenhuma das variáveis.

A Tabela 4 permite ainda identificar que 43 alunos (84\%) da universidade pública consideram os conceitos abordados sobre estrutura conceitual na disciplina de Teoria da Contabilidade importantes para o entendimento das demais disciplinas do curso. No entanto, apenas $65 \%$ dos alunos da universidade comunitária consideram esses conceitos importantes para o entendimento de outras disciplinas, sendo que 35\% da amostra afirmam ser indiferente seu estudo em relação ao entendimento das demais disciplinas do curso.

Ao realizar o teste de médias, verifica-se que para a questão 3.3 houve diferença estatisticamente significativa apenas nas respostas entre os estudantes de universidade pública e comunitária, com significância de 0,034 .

Analisando a totalidade do primeiro bloco de questões, observa-se que houve uma diferença estatisticamente significativa das respostas apenas quanto à universidade frequentada e o gênero do estudante. Sendo assim, de um modo geral, é possível afirmar que a disciplina de Teoria da Contabilidade é considerada importante para o aprendizado, sendo, na percepção dos respondentes, o aprendizado da estrutura conceitual das demonstrações contábeis necessário durante o curso e relacionado com as demais disciplinas cursadas.

A Tabela 5 refere-se ao segundo bloco de questões, as quais buscam evidenciar qual o entendimento dos acadêmicos sobre o conceito de Estrutura Conceitual das Demonstrações Contábeis.

A Tabela 5 apresenta conceitos sobre a Estrutura Conceitual das Demonstrações Contábeis em diferentes níveis de complexidade. A primeira e a terceira opção referem-se, respectivamente, a citações de Godfrey et al. (2010) e Flegm (1984), que tratam de conceitos mais amplos sobre o assunto. Já a segunda opção é uma adaptação mais básica do conceito trazido pelo CPC 00 .

Percebe-se que $84 \%$ dos alunos da universidade pública escolheram como conceitos mais adequados aqueles com maior nível de abrangência, em que 51\% optou pelo conceito de 
Godfrey et al. (2010) e 33\% por Flegm (1984). Apenas 16\% da amostra optou pelo conceito mais básico abordado pelo CPC 00 .

Tabela 5 Conceitos sobre a Estrutura Conceitual das Demonstrações Contábeis

\begin{tabular}{|c|c|c|c|c|c|}
\hline \multicolumn{5}{|l|}{ Painel A: Frequência das respostas } & \multirow{3}{*}{$\begin{array}{c}\text { Teste } \\
\text { de } \\
\text { Média }\end{array}$} \\
\hline \multirow[t]{2}{*}{ Conceitos } & \multicolumn{2}{|c|}{$\begin{array}{c}\text { Universidade } \\
\text { Pública }\end{array}$} & \multicolumn{2}{|c|}{$\begin{array}{l}\text { Universidade } \\
\text { Comunitária }\end{array}$} & \\
\hline & Frequência & $\%$ & Frequência & $\%$ & \\
\hline $\begin{array}{l}\text { Estrutura conceitual é um sistema de conceitos } \\
\text { coerentes que fluem do objetivo do relatório } \\
\text { financeiro. Os conceitos abordam as operações, } \\
\text { eventos e circunstâncias que satisfazem as } \\
\text { definições de elementos das demonstrações } \\
\text { financeiras, a determinação de quais itens devem } \\
\text { ser reconhecidos nas demonstrações financeiras } \\
\text { de uma entidade, como esses itens devem ser } \\
\text { mensurados, e como eles devem ser apresentados } \\
\text { nas demonstrações financeiras (Godfrey et al., } \\
2010 \text { ). }\end{array}$ & 26 & $51 \%$ & 43 & $52 \%$ & \multirow{4}{*}{0,460} \\
\hline $\begin{array}{l}\text { "Estrutura Conceitual para Elaboração e } \\
\text { Divulgação de Relatório Contábil-Financeiro" } \\
\text { serve como fonte dos conceitos básicos e } \\
\text { fundamentais a serem utilizados na elaboração e } \\
\text { na interpretação dos Pronunciamentos Técnicos } \\
\text { assim como na preparação e utilização das } \\
\text { demonstrações contábeis (CPC 00, 2008). }\end{array}$ & 8 & $16 \%$ & 20 & $24 \%$ & \\
\hline $\begin{array}{l}\text { A Estrutura Conceitual da Contabilidade deve ser } \\
\text { entendida como uma "constituição" para o } \\
\text { processo de estabelecimento de normas ou } \\
\text { padrões contábeis, além de fornecer um conjunto } \\
\text { de referências para solucionar questões contábeis } \\
\text { na ausência de uma norma ou padrão especifico, } \\
\text { determinar limites de julgamento na preparação } \\
\text { das Demonstrações Contábeis, e aumentar } \\
\text { comparabilidade, diminuindo o número de } \\
\text { métodos contábeis alternativos (Flegm, 1984). }\end{array}$ & 17 & $33 \%$ & 20 & $24 \%$ & \\
\hline Total & 51 & $100 \%$ & 83 & $100 \%$ & \\
\hline Painel B: Comparativo entre alunos que cur & aram e os qu & não cu & ram a disci & na & $\begin{array}{c}\text { Teste } \\
\text { de } \\
\text { Média } \\
\end{array}$ \\
\hline Conceitos & Cursaram & $\%$ & $\begin{array}{c}\text { Não } \\
\text { Cursaram }\end{array}$ & $\%$ & Sig. * \\
\hline Conceito 1 & 32 & $53 \%$ & 25 & $57 \%$ & \multirow{4}{*}{0,729} \\
\hline Conceito 2 & 13 & $21 \%$ & 8 & $18 \%$ & \\
\hline Conceito 3 & 16 & $26 \%$ & 11 & $25 \%$ & \\
\hline Total & 61 & $100 \%$ & 44 & $100 \%$ & \\
\hline
\end{tabular}

Fonte: Dados da pesquisa (2017).

$\mathrm{Na}$ universidade comunitária, $76 \%$ dos respondentes também optaram pelos conceitos com maior nível de complexidade. Porém, $24 \%$ dos alunos responderam que o conceito de estrutura conceitual mais adequado é aquele abordado pelo CPC 00, igualando-se aos $24 \%$ 


\section{PERCEPÇÃO DOS ALUNOS DE CIÊNCIAS CONTÁBEIS SOBRE A ESTRUTURA CONCEITUAL \\ BÁSICA DA CONTABILIDADE \\ DOI: http://dx.doi.org/10.5007/1983-4535.2020v13n2p1}

que optaram pelo conceito trazido por Flegm (1984). Ao realizar o teste de média, confirmase que não há diferença estatística entre as respostas dos alunos de diferentes universidades.

Ao comparar os alunos que já cursaram e os que não cursaram a disciplina de Teoria da contabilidade, percebe-se que os estudantes têm a mesma percepção sobre o conceito da Estrutura Conceitual das Demonstrações Contábeis. Fato comprovado pelo teste de média, que não demonstrou diferenças estatisticamente significativas entre as respostas dos estudantes que já cursaram e os que ainda não cursaram a disciplina. Observa-se que ambos os grupos optaram por conceitos mais complexos, sendo o Conceito 1 de Godfrey et al. (2010) o mais assinalado, correspondendo a 53\% das respostas dos que já cursaram a disciplina e 57\% dos que ainda não cursaram.

De modo geral, pode-se afirmar que por mais que assuntos do CPC 00 sejam tratados frequentemente em sala de aula, o qual constitui um dos conteúdos presentes nos planos de ensino de ambas as instituições, os alunos mostram-se capazes de entender a estrutura conceitual das demonstrações contábeis de forma mais abrangente, por meio de conceitos presentes na literatura. Tal percepção indica que os professores desta disciplina vão além do normativo contábil e possivelmente discutem com os alunos o arcabouço teórico da Teoria da Contabilidade presente em livros e artigos científicos.

A Tabela 6 apresenta os dados referente ao terceiro bloco de questões, em que se buscou analisar a interpretação teórica dos alunos quanto aos assuntos abordados na estrutura conceitual relacionado aos respondentes terem ou não cursado a disciplina de Teoria da Contabilidade.

Ao analisar a Tabela 6, percebe-se que a questão com maior percentual de acertos, tanto na universidade pública (média de $73 \%$ ) quanto na comunitária (média de 69\%), foi a questão 3.1, que se refere à Posição Patrimonial e Financeira das Empresas, um dos principais conteúdos ministrados no curso de Ciências Contábeis. É possível observar que não houve diferença estatisticamente significativa para as respostas da questão 3.1 em nenhuma das variáveis, sendo elas, a universidade, gênero, experiência profissional e ter cursado ou não a disciplina.

Já a questão com o percentual mais baixo de acertos foi a 3.2, relativa às Características Qualitativas Fundamentais e de melhoria da informação, com média de apenas $12 \%$ de acertos na universidade pública e $18 \%$ na universidade comunitária. A única 
diferença estatisticamente significativa encontrada nas respostas da questão 3.2 está na variável gênero.

Tabela 6 Questões sobre as abordagens da Estrutura Conceitual das Demonstrações Contábeis

\begin{tabular}{|c|c|c|c|c|c|c|c|c|}
\hline \multicolumn{9}{|c|}{ Painel A: Frequência das respostas } \\
\hline $\begin{array}{l}\text { Universidade } \\
\text { Pública }\end{array}$ & Já cursou & $\%$ Acertos & $\begin{array}{c}\text { Está } \\
\text { Cursando }\end{array}$ & $\%$ Acertos & $\begin{array}{c}\text { Não } \\
\text { cursou }\end{array}$ & \multicolumn{2}{|c|}{$\%$ Acertos } & $\begin{array}{c}\text { Média de } \\
\text { acertos } \\
(\%)\end{array}$ \\
\hline Questão 3.1 & 19 & $83 \%$ & 7 & $78 \%$ & 11 & \multicolumn{2}{|c|}{$58 \%$} & $73 \%$ \\
\hline Questão 3.2 & 1 & $4 \%$ & 2 & $22 \%$ & 3 & \multicolumn{2}{|c|}{$11 \%$} & $12 \%$ \\
\hline Questão 3.3 & 17 & $74 \%$ & 8 & $89 \%$ & 2 & \multicolumn{2}{|c|}{$11 \%$} & $58 \%$ \\
\hline Questão 3.4 & 7 & $30 \%$ & 2 & $22 \%$ & 2 & \multicolumn{2}{|c|}{$11 \%$} & $21 \%$ \\
\hline Questão 3.5 & 13 & $57 \%$ & 8 & $89 \%$ & 7 & \multicolumn{2}{|c|}{$37 \%$} & $61 \%$ \\
\hline Questão 3.6 & 20 & $87 \%$ & 7 & $78 \%$ & 11 & \multicolumn{2}{|c|}{$58 \%$} & $74 \%$ \\
\hline Questão 3.7 & 11 & $48 \%$ & 6 & $67 \%$ & 1 & \multicolumn{2}{|c|}{$5 \%$} & $40 \%$ \\
\hline $\begin{array}{c}\text { Média de } \\
\text { acertos (\%) }\end{array}$ & & $55 \%$ & & $64 \%$ & & \multicolumn{2}{|c|}{$27 \%$} & \\
\hline $\begin{array}{l}\text { Universidade } \\
\text { Comunitária }\end{array}$ & Já cursou & $\%$ Acertos & $\begin{array}{c}\text { Está } \\
\text { Cursando }\end{array}$ & $\%$ Acertos & $\begin{array}{c}\text { Não } \\
\text { cursou }\end{array}$ & \multicolumn{2}{|c|}{$\%$ Acertos } & $\begin{array}{c}\text { Média de } \\
\text { acertos } \\
(\%)\end{array}$ \\
\hline Questão 3.1 & 23 & $61 \%$ & 18 & $90 \%$ & 14 & \multicolumn{2}{|c|}{$56 \%$} & $69 \%$ \\
\hline Questão 3.2 & 4 & $11 \%$ & 6 & $30 \%$ & 3 & \multicolumn{2}{|c|}{$12 \%$} & $18 \%$ \\
\hline Questão 3.3 & 17 & $45 \%$ & 16 & $80 \%$ & 10 & \multicolumn{2}{|c|}{$40 \%$} & $55 \%$ \\
\hline Questão 3.4 & 7 & $18 \%$ & 7 & $35 \%$ & 5 & \multicolumn{2}{|c|}{$20 \%$} & $24 \%$ \\
\hline Questão 3.5 & 18 & $47 \%$ & 15 & $75 \%$ & 10 & \multicolumn{2}{|c|}{$40 \%$} & $54 \%$ \\
\hline Questão 3.6 & 16 & $42 \%$ & 15 & $75 \%$ & 12 & \multicolumn{2}{|c|}{$48 \%$} & $55 \%$ \\
\hline Questão 3.7 & 27 & $71 \%$ & 11 & $55 \%$ & 13 & \multicolumn{2}{|c|}{$52 \%$} & $59 \%$ \\
\hline $\begin{array}{c}\text { Média de } \\
\operatorname{acertos}(\%)\end{array}$ & & $42 \%$ & & $63 \%$ & & \multicolumn{2}{|c|}{$38 \%$} & \\
\hline \multicolumn{9}{|c|}{ Painel B: teste de médias } \\
\hline \multicolumn{2}{|c|}{ Questões } & \multicolumn{2}{|c|}{$\begin{array}{c}\text { Univ. Pública ou } \\
\text { Comunitária }\end{array}$} & $\begin{array}{c}\text { Feminino } \\
\text { Masculino }\end{array}$ & \multicolumn{2}{|c|}{$\begin{array}{l}\text { Com experiência } \\
\text { Sem experiência }\end{array}$} & \multicolumn{2}{|c|}{$\begin{array}{c}\text { Cursaram } \\
\text { Não cursaram }\end{array}$} \\
\hline \multicolumn{2}{|l|}{ Questão 3.1} & \multicolumn{2}{|c|}{ Sig: ,448 } & \multirow{2}{*}{$\begin{array}{l}\text { Sig: ,553 } \\
\text { Sig: ,045 * }\end{array}$} & \multicolumn{2}{|c|}{ Sig: , 854} & \multicolumn{2}{|c|}{ Sig: ,208 } \\
\hline Questão 3.2 & & Sig:, 6 & & & Sig: , & & & ig: , 371 \\
\hline Questão 3.3 & & Sig: , 8 & & Sig: ,736 & Sig: ,0 & & & $\mathrm{g}:, 002 *$ \\
\hline Questão 3.4 & & Sig: ,9 & & Sig: ,875 & Sig:, & & & ig: ,694 \\
\hline Questão 3.5 & & Sig:, 6 & & Sig: ,242 & Sig: , & & & ig: ,218 \\
\hline Questão 3.6 & & Sig: ,00 & & Sig: ,752 & Sig: , & & & ig: ,649 \\
\hline Questão 3.7 & & Sig: ,00 & & Sig: , 625 & Sig: , & & & g: ,004 * \\
\hline Tot: & & Sig: , 8 & & Sig: ,544 & Sig: ,0 & & & g: ,001* \\
\hline
\end{tabular}

Fonte: Elaborado pelos autores.

Ao analisar a questão 3.3, que se refere aos Princípios de Contabilidade, percebe-se que mais da metade dos estudantes de ambas as instituições de ensino acertaram a questão (média de 58\% na universidade pública e 55\% na comunitária). Quanto aos resultados dos testes de média realizados para esta questão, percebe-se que houve uma diferença estatisticamente significativa entre as respostas de alunos com e sem experiência profissional (sig: ,032) e entre os que já cursaram e não cursaram a disciplina (sig: ,002). 


\section{PERCEPÇÃO DOS ALUNOS DE CIÊNCIAS CONTÁBEIS SOBRE A ESTRUTURA CONCEITUAL

Curiosamente, a questão 3.4, que assim como a 3.2 também trata das Características Qualitativas da Informação, foi a segunda com a menor média de acertos $(21 \%$ na universidade pública e $24 \%$ na universidade comunitária), sendo que a mesma não apresentou diferença significativa em nenhuma das variáveis de comparação nos testes de média.

Em relação à questão 3.5, que trata do conceito de Custo Histórico, percebe-se que os alunos de ambas as instituições apresentaram média de acertos superior a 50\%. Apesar dos estudantes da universidade pública apresentaram um percentual de acerto ligeiramente maior (61\% contra 54\% da comunitária), essa diferença, assim como as demais comparações dos testes de média, não foram estatisticamente significativas.

Ao que se refere a questão 3.6, que trata sobre o Objetivo da Contabilidade, percebe-se que apesar de em ambas as instituições mais da metade dos estudantes terem acertado a questão, os alunos da universidade pública demonstraram um maior entendimento sobre o tema, com uma média de acertos de $74 \%$, aproximadamente $19 \%$ a mais do que os alunos da universidade comunitária, essa diferença também foi estatisticamente significativa no teste de médias.

A questão 3.7, que se refere ao conteúdo de Valor Justo, teve média de acerto de apenas $40 \%$ dos alunos da universidade pública, enquanto na universidade comunitária foi de $59 \%$, o que demonstra que os alunos desta última apresentam um entendimento mais robusto do tema, confirmado pelo teste de média, o qual revelou uma diferença estatisticamente significativa de 0,002 na variável universidade. Vale a pena ressaltar que além da variável universidade, o fato de os alunos terem ou não cursado a disciplina também implicou em uma diferença significativa de 0,004 no teste de média para esta questão.

Esses resultados revelam, que, na percepção dos respondentes, o aspecto da estrutura conceitual das demonstrações contábeis que mais gera dúvidas no meio acadêmico de ambas as universidades é referente às Características Qualitativas da Informação Contábil. Além disso, pode-se afirmar quanto à amostra abordada nesta pesquisa, que os alunos da universidade comunitária apresentam maior dificuldade na questão que trata sobre o Objetivo da Contabilidade, enquanto os alunos da universidade pública apresentam maiores dificuldades no que se diz respeito ao conteúdo de valor justo.

A Tabela 6 também permite observar que os alunos que estão cursando a disciplina de Teoria da Contabilidade apresentam média maior de acertos de questões do que os alunos que já cursaram a disciplina. Uma causa provável para esse resultado é que o conteúdo sobre 
estrutura conceitual das demonstrações contábeis esteja mais presente na memória dos acadêmicos que estão estudando esses aspectos na disciplina atualmente, do que os que já estudaram há um ano, ou aqueles que ainda não tiveram a disciplina.

Além disso, também é possível verificar que embora em algumas questões específicas não haja diferença estatisticamente significativa entre os alunos que já cursaram e os que não cursaram a disciplina, ao verificar o contexto geral das questões do bloco três, as mesmas apresentam uma diferença significativa de 0,001 entre as respostas dos alunos que já cursaram e que ainda não cursaram a disciplina. O fato de os alunos terem ou não experiência profissional também apresentou significância de 0,021 no teste de média total.

Nota-se ainda que apenas 4 das 7 questões analisadas tiveram alguma variável com diferença estatisticamente significativa, quanto à diferença de respostas entre estudantes da universidade pública ou comunitária, do gênero masculino ou feminino, com ou sem experiência profissional, e ter cursado ou não a disciplina de Teoria da Contabilidade.

$\mathrm{Na}$ literatura ainda não há um estudo que tenha analisado o entendimento dos acadêmicos de Ciências Contábeis sobre o conceito e a utilidade da estrutura conceitual contábil. Porém, os achados de Cruz et al. (2011) revelaram que o nível de percepção de entendimento dos docentes sobre a estrutura conceitual foi elevada e que existem diferentes níveis de percepções quando consideradas as linhas de pesquisas desses docentes, porém, não houve diferença entre as médias quando consideradas algumas variáveis de comparação no estudo.

Apesar da presente pesquisa ser realizada em um contexto diferente, analisar alunos ao invés de professores, assemelha-se ao estudo de Cruz et al. (2011) no que se refere à percepção dos participantes sobre o entendimento da estrutura conceitual, com algumas diferenças significativas de acordo com características e contextos específicos de cada indivíduo.

No que se refere aos resultados sobre a percepção dos alunos acerca da importância da disciplina de Teoria da Contabilidade, o presente estudo corrobora o estudo de Piccoli et al. (2015), no qual estudantes também afirmam que a disciplina de Teoria da Contabilidade é importante para o seu aprendizado e para o entendimento das demais disciplinas, estando fortemente relacionada com as demais disciplinas cursadas. Porém, nossos resultados se diferem desse estudo prévio por abordar não apenas o contexto geral da disciplina de Teoria 
da Contabilidade, mas direcionar o foco para o entendimento dos acadêmicos sobre a estrutura conceitual das demonstrações contábeis.

\section{CONCLUSÕES}

O objetivo desta pesquisa foi analisar o entendimento dos alunos do Cursos de Ciências Contábeis de duas universidades localizadas em Santa Catarina, sendo uma de caráter público e outra comunitária, sobre o conceito e a utilidade da estrutura conceitual no ensino de contabilidade. $\mathrm{O}$ estudo identificou como perfil dos respondentes, que a maioria dos alunos é do gênero feminino, com faixa etária entre 20 e 23 anos. Cerca 56\% tem experiência profissional na área contábil e $46 \%$ já cursaram a disciplina de teoria da contabilidade.

De modo geral, verificou-se que para a maioria dos alunos, a disciplina de Teoria da Contabilidade é considerada importante para o aprendizado. Constatou-se ainda que conceitos mais abrangentes sobre a estrutura conceitual das demonstrações contábeis são os mais percebidos pelos acadêmicos pesquisados. $\mathrm{O}$ aspecto da estrutura conceitual que mais gera dúvidas no meio acadêmico de ambas as universidades está relacionado às características qualitativas da informação contábil, o que serve para reforçar o olhar das universidades para o foco que tem sido dado no ensino dessas características ao abordar a estrutura conceitual contábil nos cursos de graduação. Além disso, os alunos da universidade pública apresentam maiores dificuldades no que se diz respeito ao conteúdo de Valor Justo, enquanto os alunos da universidade comunitária apresentaram mais dificuldades quanto ao objetivo da Contabilidade.

Verificou-se também que os alunos que estão cursando a disciplina de Teoria da Contabilidade apresentaram maior média de acertos de questões do que os alunos que já cursaram a disciplina. Infere-se, a partir disso, que os conceitos podem não estar sendo de fato assimilados pelos alunos durante o curso, visto que acabam sendo "esquecidos" em parte após cursarem a disciplina. No entanto, ao comparar apenas os alunos que já cursaram com os que ainda não cursaram a disciplina, foi possível verificar uma diferença estatisticamente significativa no contexto geral das respostas, concluindo-se que o fato de cursar a disciplina é importante para o entendimento dos conceitos relativos à Teoria da Contabilidade.

Diante dos resultados e considerações finais aqui expostas, pode-se concluir que as contribuições pretendidas na presente pesquisa foram alcançadas, possibilitando a ampliação da literatura sobre a estrutura conceitual no ensino de contabilidade e refletindo na 
importância da explicação desse conteúdo na graduação. Permitiu-se também a comparação sobre as formas de ensino e dúvidas particulares entre estudantes de universidade pública e comunitária, fornecendo subsídios sobre como futuros profissionais da área contábil percebem a importância da estrutura conceitual para sua formação.

Este estudo apresenta pelos menos duas contribuições, principalmente relacionadas ao ensino da disciplina de Teoria da Contabilidade. Primeiramente, destaca quais as maiores dificuldades dos alunos em relação aos conceitos trabalhados na disciplina (características qualitativas e conceito de valor justo), o que contribui para que as Universidades e Professores da referida disciplina modifiquem seus planos de ensino, procurando enfatizar tais temas de maneira mais efetiva. Também demonstra que os conceitos aprendidos no decorrer da disciplina são em parte "perdidos" no momento seguinte, o que pode indicar a necessidade de alterações na didática utilizada pelos professores desta disciplina.

Como limitação do presente estudo, identifica-se o fato dos dados serem levantados em apenas duas universidades do Estado de Santa Catarina, sendo uma delas pública e outra comunitária, não sendo possível a comparação com universidade privada, por motivos de acessibilidade. Outro fator limitante é que os dados foram coletados apenas com acadêmicos da terceira, quinta e sétima fase, caracterizando os que irão cursar, os que estão cursando e os que já cursaram a disciplina de teoria da contabilidade, os alunos dos demais semestres não fizeram parte da amostra. Portanto, os resultados deste estudo não podem ser generalizados para além da amostra, mas sugere-se a ampliação deste para outras universidades de todos o país.

O presente trabalho foi realizado com apoio da Coordenação de Aperfeiçoamento de Pessoal de Nível Superior - Brasil (CAPES) - Código de Financiamento 001.

\section{REFERÊNCIAS}

BORBA, J. A.; POETA, F. Z.; VICENTE, E. F. R. Teoria da contabilidade: uma análise da disciplina nos programas de mestrado brasileiros. Sociedade, Contabilidade e Gestão, v. 6, n. 2, 2011.

COMISSÃO DE VALORES MOBILIARIOS. Deliberação n. ํ 29. Brasília: CVM. (1986). em:

http://www.cvm.gov.br/export/sites/cvm/legislacao/deliberacoes/anexos/0001/deli029.pdf.

COMITE DE PRONUNCIOAMENTOS CONTÁBEIS. Estrutura Conceitual para Elaboração e Divulgação de Relatório Contábil-Financeiro. CPC. (2008). em: http://portalcfc.org.br/wordpress/wp-content/uploads/2013/01/livro_CPC2.pdf. 
CRUZ, C.; FERREIRA, A. C.; SZUSTER, N. Estrutura Conceitual da Contabilidade no Brasil: Percepção dos Docentes dos Programas de Pós-Graduação Stricto Sensu em Ciências Contábeis. Revista Pensar Contábil, v. 13, n. 50, p. 53-63, 2010.

GLAUTIER, M. W. E.; UNDERDOWN, B. Accounting theory and practice. 5. ed., London: Pitman Publishing, 1995.

GODFREY, J.; HODGSON, A.; TARCA, A.; HAMILTON, J.; HOLMES, S. Accounting theory. 7. ed., Milton: Queensland, 2010.

HENDRIKSEN, E. S.; VAN BREDA, M. F. Teoria Da Contabilidade. 5. Ed. São Paulo: Atlas, 2010.

IUDÍCIBUS, S.; MARTINS, E.; CARVALHO, L. N. Contabilidade: aspectos relevantes da epopéia de sua evolução. Revista Contabilidade \& Finanças, v. 16, n. 38, p. 7-19, 2005.

IUDÍCIBUS, S. O verdadeiro significado de uma teoria. Revista Brasileira de Contabilidade, v. 25, n. 97, p. 21-23, 1997.

IUDÍCIBUS, S. D. Teoria da Contabilidade: evolução e tendências. Revista de Contabilidade do Mestrado em Ciências Contábeis da UERJ, v. 17, n.2, p. 5-13, 2012.

FLEGM, E. H. Accounting: how to meet the challenges of relevance and regulation. New York: John Wiley \& Songs, 261, 1984.

MADEIRA, G. J.; MENDONÇA, K. F. C.; ABREU, S. M. A disciplina teoria da contabilidade nos exames de suficiência e provão. Contabilidade Vista \& Revista, v. 14, p. 103-122, 2003.

PAULO, E. Comparação da estrutura conceitual da contabilidade financeira: experiência brasileira, norte-americana e internacional. Dissertação de mestrado, Universidade Federal da Paraíba, João Pessoa, PB, Brasil, 2002.

PELEIAS, I. R.; SILVA, G. P.; SEGRETI, J. B.; CHIROTTO, A. R. Evolução do ensino da contabilidade no Brasil: uma análise histórica. Revista Contabilidade \& Finanças, v. 18, p. 19-32, 2007.

PEREIRA, A. C. Relato de um momento importante: reflexões dos alunos da disciplina Teoria da Contabilidade do Mestrado da USP, trinta anos depois. [Editorial]. Revista Contabilidade \& Finanças, v. 10, n. 46, 2008.

PICCOLI, M. R.; CHIARELLO, T. C.; KLANN, R. C. A percepção dos acadêmicos sobre conceitos abordados na disciplina de Teoria da Contabilidade. Revista de Gestão, Finanças e Contabilidade, v. 5, n. 1, p. 40-57, 2015.

PINHEIRO, F. A. O Postulado do Usuário: incentivo ao desenvolvimento da Teoria da Contabilidade e do Contabilista. Caderno de Estudos, n. 16, p. 01-08, 1997. 
SACRAMENTO, C. O. D. J. O ensino de teoria da contabilidade no Brasil. Caderno de Estudos, n. 18, p. 01-10, 1998.

WATTS, R. L.; ZIMMERMAN, J. L. Positive accounting theory. Englewood Cliffs: Prentice Hall, 1986. 